\title{
Morphological Comparison Between the Large Metatarsal Bone of Zebu bull (Bos Taurus indicus) and Egyptian Baladi bull (Bos Taurus Taurus): New Insights by Gross, Morphometric, and Computed Tomography
}

\author{
Ashraf A. El Sharaby, ${ }^{1}$ Mohammed Ali Abd El-Fatah, ${ }^{1}$ Mohamed M. A. Abumandour, ${ }^{2}$ and Ahmed G. Nomir ${ }^{1}$
}

${ }^{1}$ Department of Anatomy and Embryology, Faculty of Veterinary Medicine, Damanhour University, Egypt.

${ }^{2}$ Department of Anatomy and Embryology, Faculty of Veterinary Medicine, Alexandria University

Disclose and conflicts of interest: none to be declared by all authors

\begin{abstract}
Introduction: the current study was prepared to provide a complete anatomical and morphometric comparison description of the metatarsal bone in the zebu bull and Egyptian Baladi bull using the anatomical cross-section and computed tomography technique.

Material and Methods: in all examined specimens of zebu and Baladi bull, two large metatarsal bones were identified, apparently fused, and presented common morphological features. In the metatarsal bones of the two species, a fusion of the proximal extremity with the shaft was apparent meanwhile the distal extremity was clearly separated from the shaft especially in the Baladi metatarsal bones. The obtained tomographic images provided an excellent modality for the skeletal and soft tissue architecture of the Egyptian Baladi and Zebu metatarsal bones.

Results: in Baladi bull, the proximal osseus septum was represented by a short crest meanwhile it was relatively long in Zebu bull. In addition, the distal osseous septum is longer and more extensive in Zebu metatarsi than in those the Egyptian Baladi bull. In Zebu bull, the medullary cavity is incompletely divided by a vertical bony septum, which is interrupted at the middle third of the shaft. Morphometric data revealed significant variations among the dimensions of the metatarsal bones of the two examined bull species.

Conclusions: except for the diameter of the distal extremity, all the recorded parameters were greater in Zebu metatarsi compared to those of the Egyptian Baladi bull.

Keywords: Computed tomography; Cross-sectional; Large Metatarsal bone; Osseous septum; Zebu bull; Egyptian Baladi bull.
\end{abstract}

\section{Introduction}

The Zebu bull, also known as the humped bull (Bos Taurus indicus, Linnaeus, 1758) is a subspecies of Bos Taurus species, Bos Genus, Bovidae family. They are characterized by fatty hump on their shoulder in which they adapted to living in tropical environments ${ }^{3,11}$. They are bred mainly for meat with little amount of milk production ${ }^{11}$. The Egyptian Baladi bull (Bos Taurus Taurus) is a subspecies of Bos Taurus species, Bos Genus, Bovidae family ${ }^{15}$. They are morphologically described between European, African and Zebu bull, and characterized by relative heat tolerance ${ }^{9}$. Egyptian Baladi cows are bred mainly for milk and meat production, and their milk yield is really very modest ${ }^{13}$.

In ungulates, the bones of their metapodia (metacarpi and metatarsi) are among the important limb long bones and play a vital role to load their relative high musculature and to bear their heavy weight. In addition, these bones are considered to be a predilection seats of most surgical disorders affecting the limbs leading to lameness. Painful manifestations in the limbs are reflected directly on milk yield, meat production as well as ability to work in draft animals ${ }^{5,8,10}$. The gross morphology of these bones is well described in livestock with minor comparative points to the ruminants $5^{5,7,12}$. The gross anatomical features of these bones and their functional structure were described ${ }^{1,2,4}$. However, the available anatomical data about the skeletal components of zebu (Bos Taurus indicus) are scanty. The purpose of the current work was to provide gross and morphometric comparison between the metatarsal bone of zebu (Bos Taurus indicus) and Egyptian Baladi bull (Bos Taurus Taurus) with the aid of computed tomography. The obtained data were discussed with the previously published data on the different animal species.

\section{Material and Methods}

\section{Sample collection:}

The present study was conducted on twelve pes regions of 1.5 years old and clinically heathy zebu bull (Bos Taurus indicus) and Egyptian Baladi bull 
(Bos Taurus taurus). Six specimens of each species were collected from the Egyptian armed forces and Damanhour slaughterhouses at Ismailia and ElBehera governorates, respectively. Each specimen was dislocated proximally at the tarsometatarsal joint and distally at the tarsometatarsal joint and transferred to the CT laboratory center within two hours after slaughtering to reduce the post-mortem changes. We followed the adopted guidelines for animal welfare of Ethics Committee of the Faculty of Veterinary Medicine, Damanhour University. The anatomical terms follow the NOMINA ANATOMICAVETERINARIA, $2017^{14}$.

\section{Computed tomography (CT):}

The obtained specimens were scanned using Toshiba Astesion Super 4 Multi-slice 4 CT apparatus at $120 \mathrm{KV}$ and $150 \mathrm{mAs}$. The CT images were $1 \mathrm{~cm}$ slice thickness with $1 \mathrm{~cm}$ interval. For bone windows, we adapted the apparatus with 200 Hounsfield units in the windows width and 1600 Hounsfield units in the windows level, meanwhile 30 Hounsfield units in the windows width and 290 Hounsfield units in the windows level were adjusted for soft window ${ }^{1}$.
For documentation, the scanned CT images were printed using CT digital printer in addition to digital workstation images were saved on a hard drive for offline investigation using RadiAnt DICOM Viewer software; version 2020.2.3.

\section{Preparation of anatomical sections:}

After each pes specimen of the two species was scanned by $\mathrm{CT}$, it has been macerated and the metatarsal bones were prepared for gross and transverse-section examinations. They were placed on the table with band saw and serial transverse sections were cut approximately $2-3 \mathrm{~cm}$ apart. The collected sections were photographed using canon (EOS 2000D 18-55 IS, 24.1 MP, DSLR digital camera), and the selected surfaces were faced toward the camera.

\section{Morphometric analysis:}

A custom-designed list of anticipated parameters for the metatarsal bones of Zebu and Egyptian Baladi bull were prepared on the base of gross morphology and CT slices using RadiAnt DICOM Viewer software. The collected data were tabulated (Tables 1-2).

Table 1: Morphometric dimensions of the metatarsal bones in Zebu (Bos Taurus indicus) and Egyptian Baladi bull (Bos Taurus Taurus).

\begin{tabular}{l|l|c|c}
\hline \multicolumn{1}{c|}{ Features } & \multicolumn{1}{c}{ Item } & Egyptian Baladi bull (cm) & Zebu bull (cm) \\
\hline \multirow{2}{*}{ Whole bone } & Length (proximodistal) & 24.85 & 25.88 \\
\hline Proximal extremity & Diameter & 20 & 20.5 \\
\hline \multirow{5}{*}{ Shaft } & Proximal osseus septum & 2.6 & 7.85 \\
\cline { 2 - 4 } & Length of dorsal surface & 2.7 & 3 \\
\cline { 2 - 4 } & Length of planter surface & 3.37 & 3.6 \\
\cline { 2 - 4 } & Width (mediolateral) & 1.26 & 1.82 \\
\cline { 2 - 4 } & Compact layer thickness & 11.2 & 1.62 \\
\cline { 2 - 4 } & Diameter & 8.35 & 10.10 \\
\cline { 2 - 4 } & Distal osseus septum & 19.5 & 18.3 \\
\hline \multirow{2}{*}{ Distal extremity } & Diameter & & \multirow{2}{*}{1} \\
\hline
\end{tabular}

Table 2: Morphometric dimensions at the proximal, middle, and distal thirds of the metatarsal bones in Zebu (Bos Taurus indicus) and Egyptian Baladi bull (Bos Taurus Taurus) as measured by Radiant software.

\begin{tabular}{l|c|c|c|c}
\hline \multirow{3}{*}{ Shaft dimensions } & \multicolumn{2}{|c|}{ Egyptian Baladi bull } & \multicolumn{2}{c}{ Zebu bull } \\
\cline { 2 - 5 } & Mediolateral width & Dorsoplantar width & Mediolateral width & Dorsoplantar width \\
\hline \multirow{3}{*}{ Proximal one third } & 4.02 & 3.67 & 4.74 & 4.06 \\
\cline { 2 - 5 } & 3.32 & 3.42 & 4.4 & 4.86 \\
\cline { 2 - 5 } & 3.3 & 3.24 & 4.28 & 3.72 \\
\hline \multirow{3}{*}{ Middle one third } & 3.64 & 3.06 & 4.21 & 4.89 \\
\cline { 2 - 5 } & 3.86 & 2.94 & 4.21 & 3.51 \\
\hline \multirow{2}{*}{ Distal one third } & - & - & 4.83 & 3.29 \\
\cline { 2 - 5 } & 4.49 & 2.46 & 6.46 & 3.88 \\
\hline
\end{tabular}




\section{Results}

Gross morphology of large metatarsal bones of Egyptian Baladi and zebu bull:

In all examined specimens of zebu and Baladi bull, two large metatarsal bones were identified, apparently fused, and presented common morphological features (Figs. 1-2). The proximal extremity had two articular facets that were separated by a notch and ridge dorsally. The medial articular facet was larger than the lateral one. The shaft was typically cylindrical and four sided with two surfaces. The dorsal surface of the proximal extremity had metatarsal tuberosity on its medial aspect. A dorsal and median metatarsal groove extended along the entire length of the bone, but it was clearer distally. In addition, nutrient foramen was observed at about the level of nutrient foramen i.e., about $2.5 \mathrm{~cm}$ above the distal extremity of the metatarsal bones. The plantar surface carried a shallower median longitudinal palmar metatarsal groove. The distal extremity was divided by intercondyloid groove into two trochleae each of which was formed from two condyles separated by a prominent sagittal ridge. The medial condyle was slightly larger and more prominent than the lateral one.

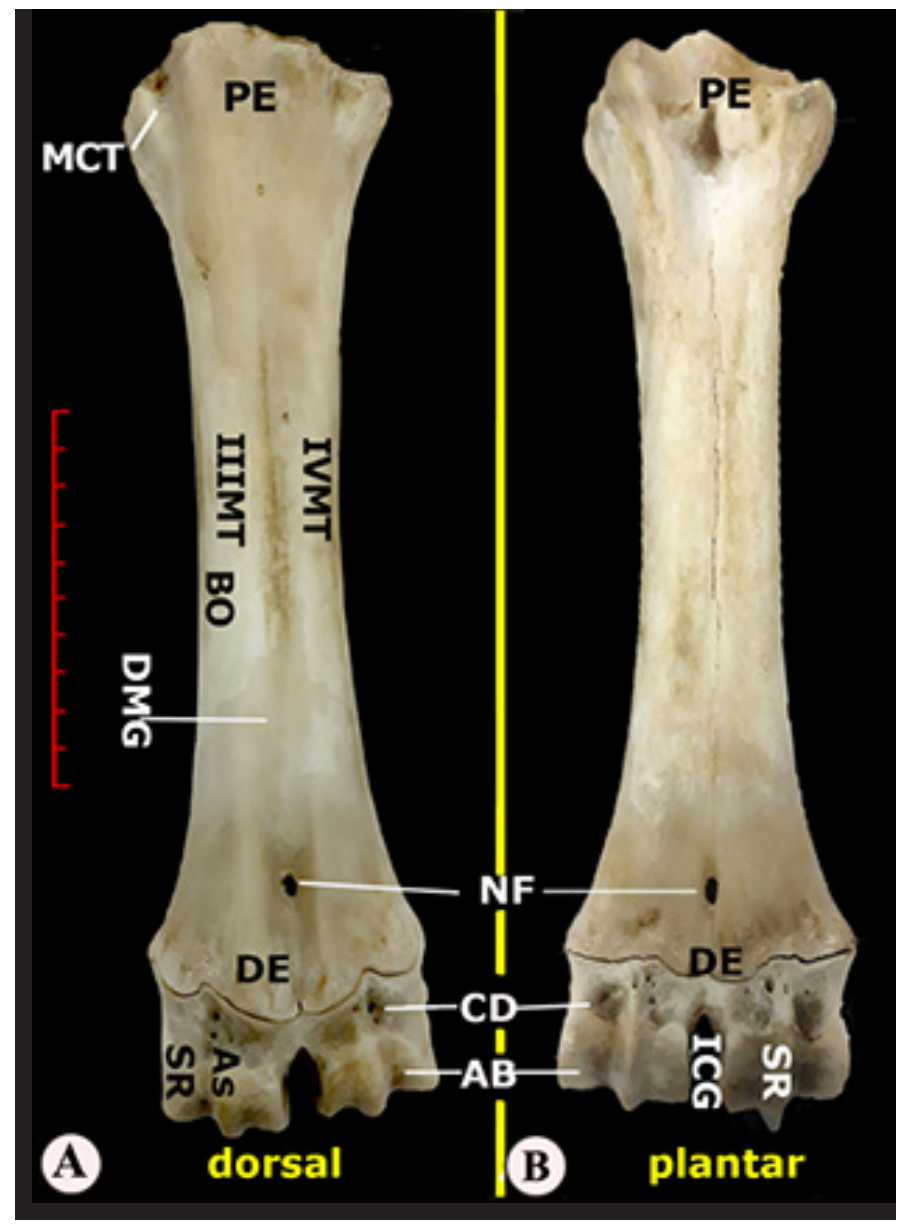

Figure 1: Morphology of the metatarsal bones of Egyptian Baladi bull. A. Dorsal surface; B. Plantar surface. Proximal extremity (PE), distal extremity (DE), body (BO), dorsal metatarsal groove (DMG), Nutrient foramen (NF), medial metatarsal tuberosity (MCT), inter-condyloid groove (ICG), sagittal crest (SR), abaxial part $(A B)$, axial part (AS).

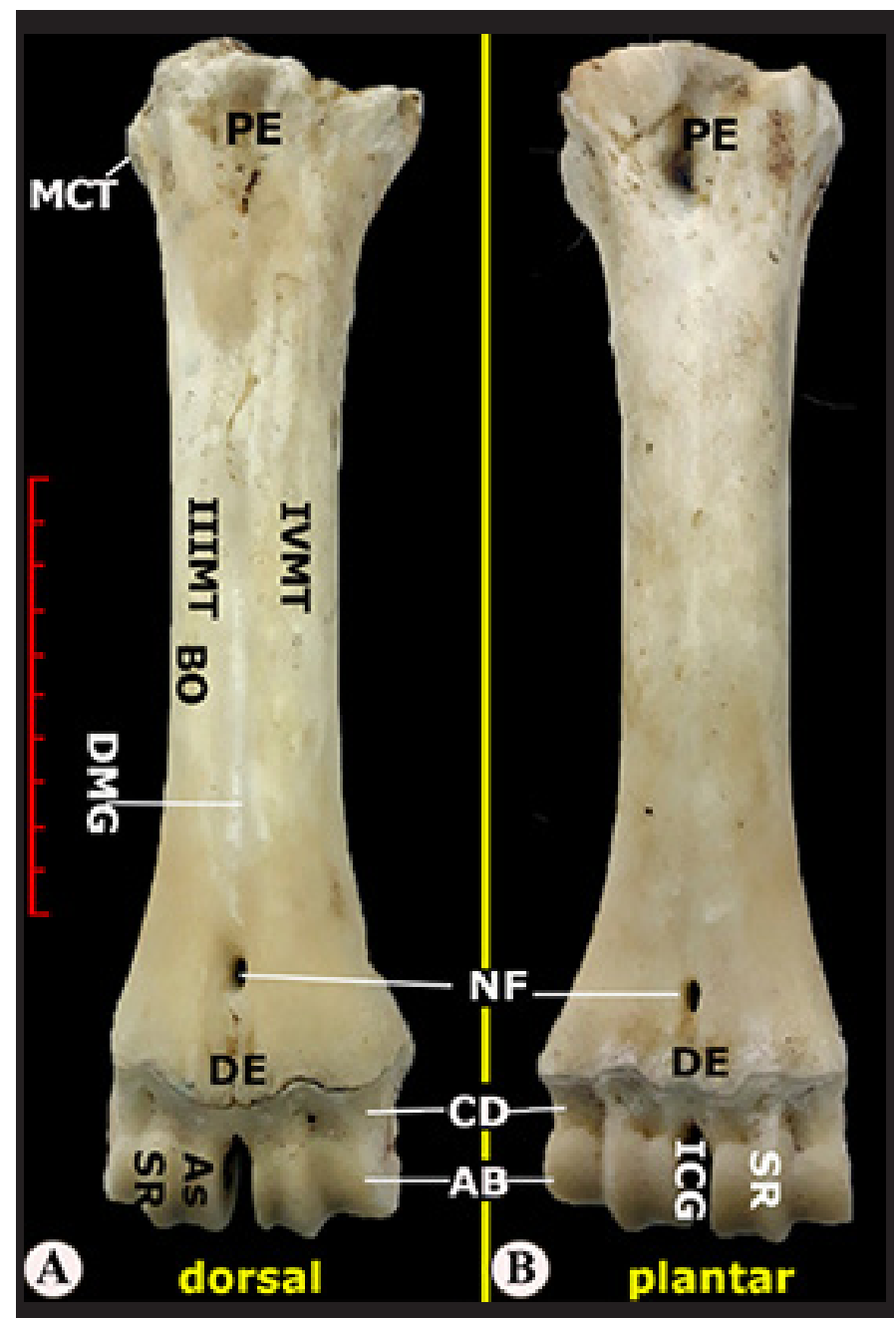

Figure 2. Morphology of the metatarsal bones of zebu bull A. Dorsal surface; $B$. Plantar surface. Proximal extremity (PE), distal extremity (DE), body (BO), dorsal metatarsal groove (DMG), nutrient foramen (NF), medial metatarsal tuberosity (MCT), inter-condyloid groove (ICG), sagittal crest (SR), abaxial part (AB), axial part (AS).

In the metatarsal bones of the two examined species, fusion of the proximal extremity with the shaft was apparent meanwhile the distal extremity was clearly separated from the shaft specially in the Baladi metatarsal bones.

Computed tomography of metatarsal region of Egyptian Baladi and zebu bull:

The obtained tomographic images provided an excellent modality for skeletal and soft tissue architecture of the Egyptian Baladi (Figs.3-6) and Zebu metatarsal bones (Figs.7-11). The images had higher density for the bones and excellent delineation between the cortex and medulla of bones, and the trabecular pattern of the cancellous bone was clearly shown. All bone structures including the epiphysis and diaphysis as well as medullary cavity of the metatarsus were seen on the transverse CT images starting proximally at the level of the tibiotarsus joint and continuing in a row distal ward till the level of the tarsometatarsal joint. The average number of the obtained slices was 300 slices with a $0.5 \mathrm{~mm}$ slice thickness. 


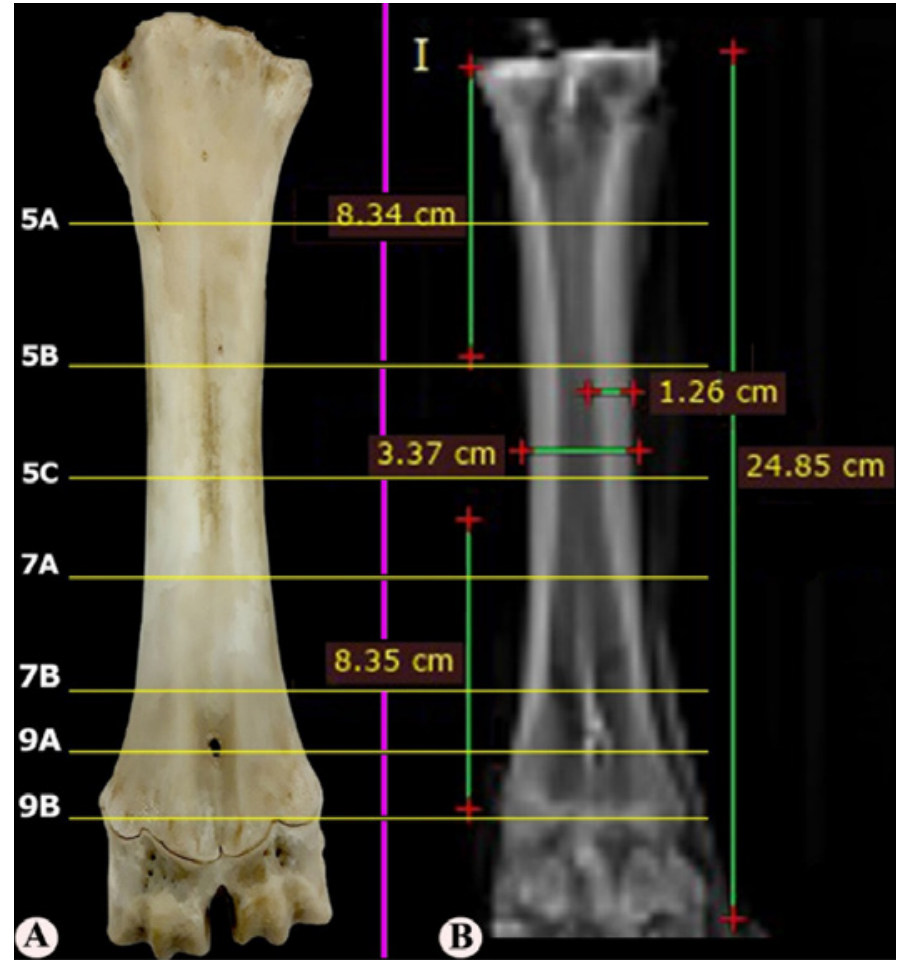

Figure 3. Planes of the selected transverse seven sections of the metatarsal bones in comparison with their CT scans (bone window) in Egyptian Baladi bull. The figure shows that the average length of the large metatarsal bone was about $24.85 \mathrm{~cm}$. The thickness of the compact layer in the middle third was $1.26 \mathrm{~cm}$. A short crest instead of the typical proximal osseus septum was detected in some specimens meanwhile the distal osseous septum extended upward for about $8.35 \mathrm{~cm}$ above the distal extremity.

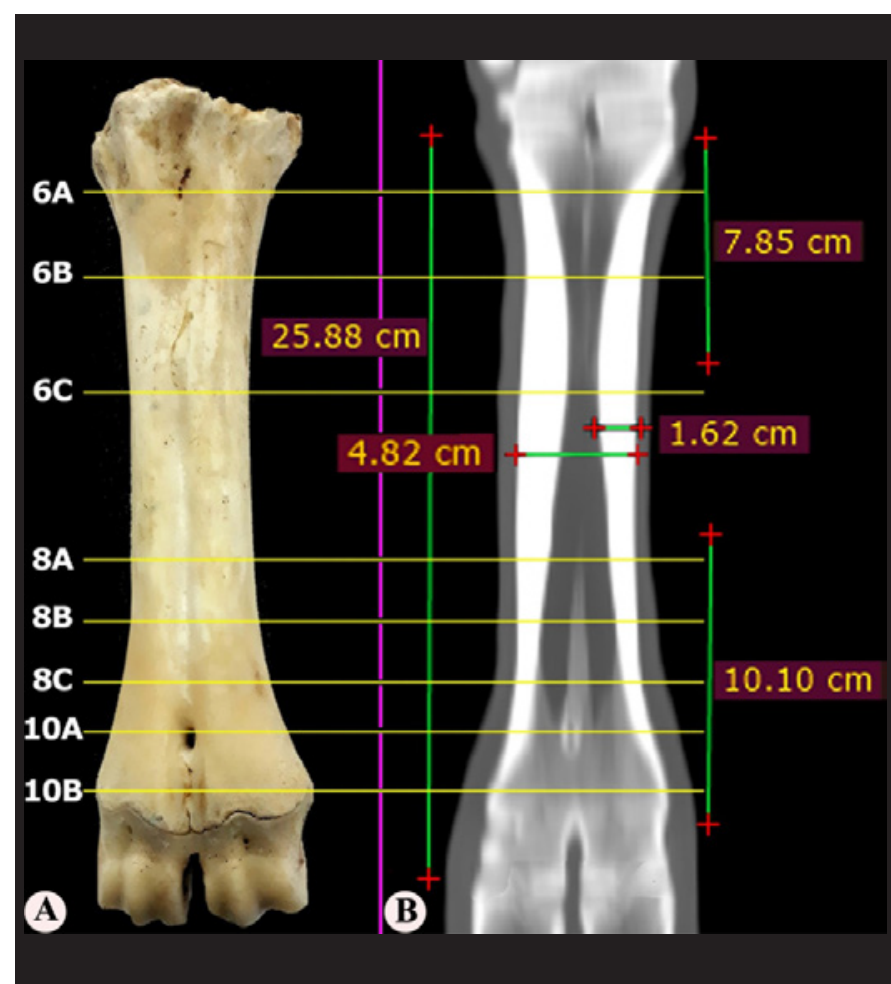

Figure 4. Planes of the selected transverse eight slices of the metatarsal bones in comparison with their CT scans (bone window) in zebu bull. The figure showed that the average length of the large metatarsal bone was about $25 \mathrm{~cm}$, the length of the proximal, middle, and distal phalanx were $6.58 \mathrm{~cm}, 3.61 \mathrm{~cm}$, and $4.72 \mathrm{~cm}$ respectively. The thickness of the compact layer in the middle third was $1.62 \mathrm{~cm}$. The length of the proximal osseous septa extended about $7.85 \mathrm{~cm}$ below the proximal extremity and the distal osseous septa extended about $10.10 \mathrm{~cm}$ above the distal extremity.
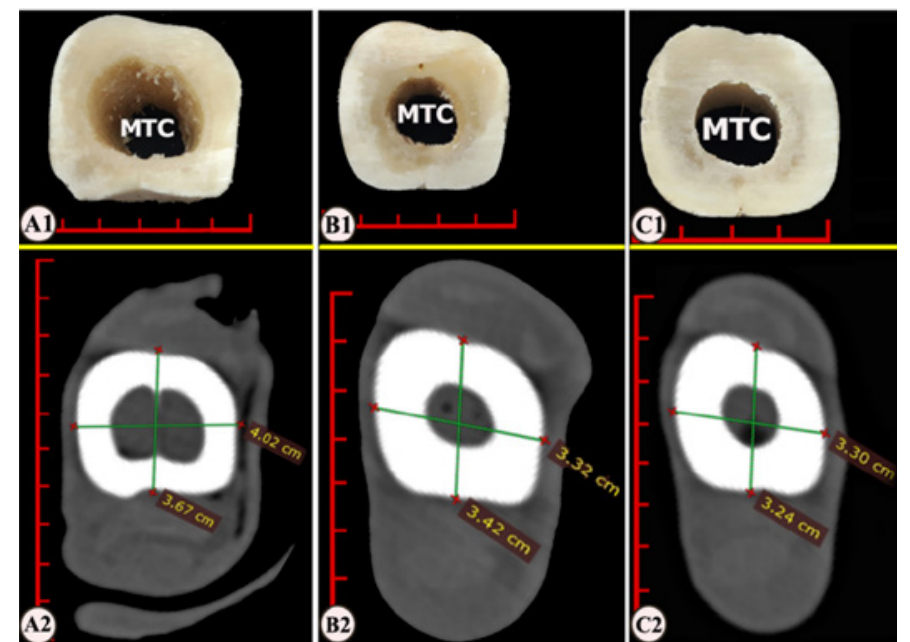

Figure 5. Transverse sections of the metatarsal bone of Egyptian Baladi bull. A1. Transverse anatomical section at the level of the proximal extremity of the metatarsal bones. The longitudinal and transverse diameter of the metatarsal bone were about $3.67 \mathrm{~cm}$ and $4.02 \mathrm{~cm}$, respectively. A2. The most relevant transverse bone window $\mathrm{CT}$ section.

The longitudinal and transverse diameter of the metatarsal bone were $3.06 \mathrm{~cm}$ and $3.64 \mathrm{~cm}$ respectively. Notice the incomplete proximal osseous septum (POS). B1. Transverse anatomical section at the level of $3 \mathrm{~cm}$ below the proximal extremity of the metatarsal bones. B2. The most relevant transverse bone window CT section. The longitudinal and transverse diameter of the metatarsal bone were $3.42 \mathrm{~cm}$ and $3.32 \mathrm{~cm}$, respectively.

C1. Transverse anatomical section at the level of $8 \mathrm{~cm}$ below the proximal extremity of the metatarsal bones. C2. The most relevant transverse bone window $\mathrm{CT}$ section. The longitudinal and transverse diameter of the metatarsal bone were $3.24 \mathrm{~cm}$ and $3.30 \mathrm{~cm}$, respectively.

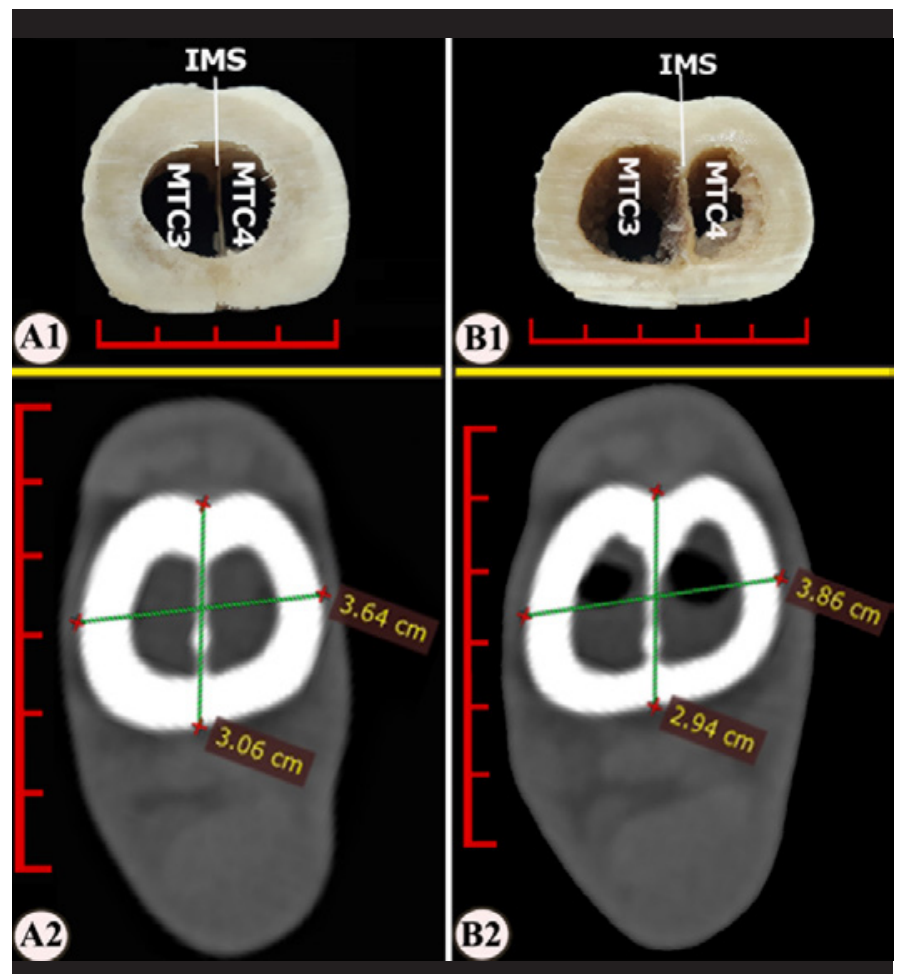

Figure 6. Transverse sections of the metatarsal bone of Egyptian Baladi bull. A1. Transverse anatomical section at the middle third about $10 \mathrm{~cm}$ above the distal extremity of the metatarsal bones. A2. The most relevant transverse bone window CT section. The longitudinal and transverse diameter of the metatarsal bone were $3.06 \mathrm{~cm}$ and $3.64 \mathrm{~cm}$ respectively.

B1. Transverse anatomical section at the distal third at the level of $7.5 \mathrm{~cm}$ above the distal extremity of the metatarsal bones. $\mathrm{B} 2$. The most relevant transverse bone window CT section. The longitudinal and transverse diameter of the metatarsal bone were $2.94 \mathrm{~cm}$ and $3.86 \mathrm{~cm}$, respectively. Notice the presence of the distal osseous septum (IMS). Clear septation of the distal osseous septum within the medullary cavity. 

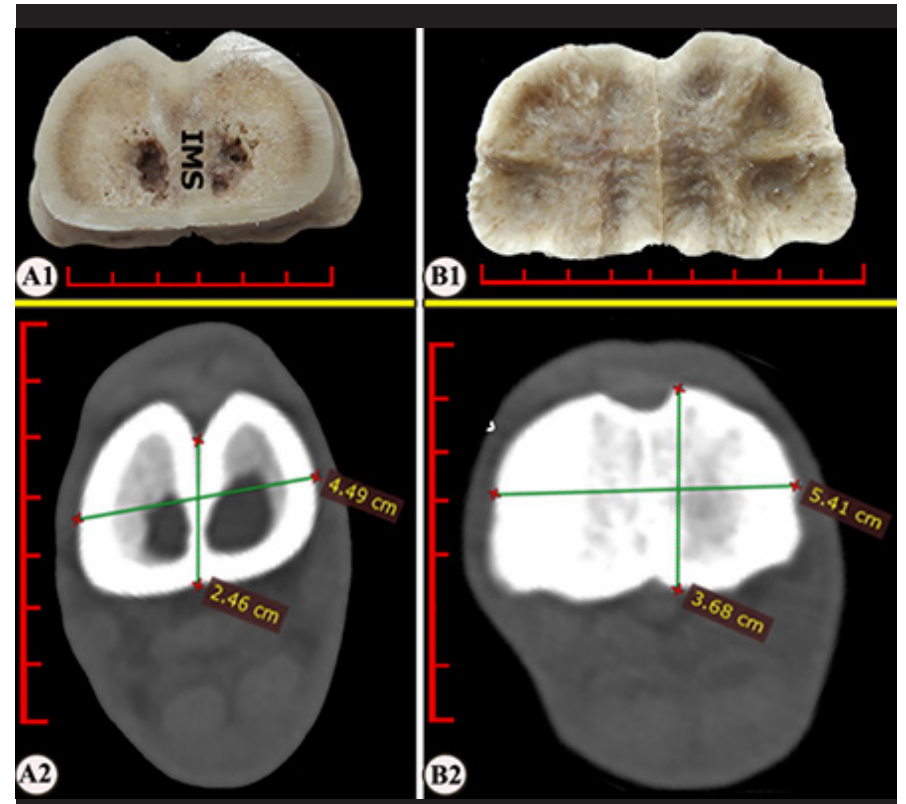

Figure 7. Transverse sections of the metatarsal bone of Egyptian Baladi bull. A1. Transverse anatomical section at the distal third at the level of about 2.5 $\mathrm{cm}$ above the distal extremity of the metatarsal bones. A2. The most relevant transverse bone window CT section. The longitudinal and transverse diameter of the metatarsal bone were $2.46 \mathrm{~cm}$ and $4.49 \mathrm{~cm}$ respectively.

B1. Transverse anatomical section at the distal extremity of the metatarsal bones. B2. The most relevant transverse bone window СT section. The longitudinal and transverse diameter of the metatarsal bone were $3.68 \mathrm{~cm}$ and $5.41 \mathrm{~cm}$ respectively. Notice the presence of the distal osseous septum (IMS). Clear septation of the distal osseous septum within the medullary cavity.

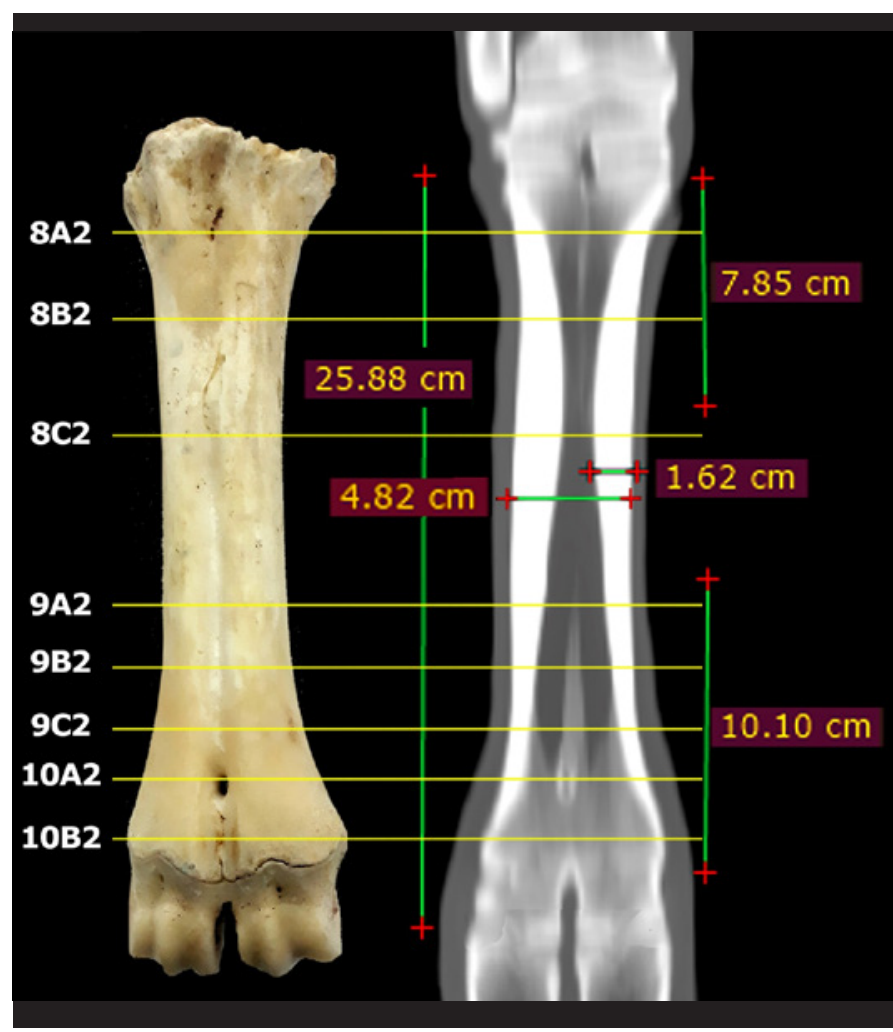

Figure 8. Planes of the selected transverse eight slices of the metatarsal bones in comparison with their CT scans (bone window) in zebu bull. The figure showed that the average length of the large metatarsal bone was about $25 \mathrm{~cm}$, the length of the proximal, middle, and distal phalanx were $6.58 \mathrm{~cm}, 3.61 \mathrm{~cm}$, and $4.72 \mathrm{~cm}$ respectively. The thickness of the compact layer in the middle third was 1.62 $\mathrm{cm}$. The length of the proximal osseous septum extended about $7.85 \mathrm{~cm}$ below the proximal extremity and the distal osseous septum extended about $10.10 \mathrm{~cm}$ above the distal extremity.

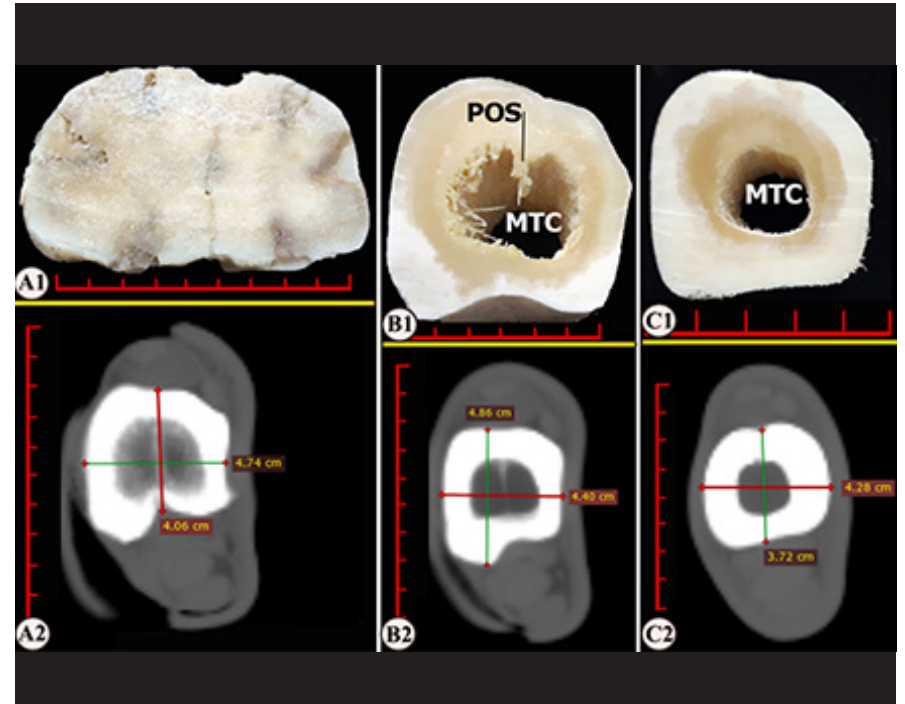

Figure 9. Transverse sections of the metatarsal bones of Zebu bull.

A1. Transverse anatomical section at the level of the proximal one third of the metatarsal bones $2 \mathrm{~cm}$ from the proximal extremity. A2. The most relevant transverse bone window CT section. The longitudinal and transverse diameter of the metatarsal bone were $4.06 \mathrm{~cm}$ and $4.74 \mathrm{~cm}$ respectively. Notice the presence of complete proximal osseous septum (POS).

B1. Transverse anatomical section at the level of the proximal one third of the metatarsal bones at about $5 \mathrm{~cm}$ below the proximal extremity. B2. The most relevant transverse bone window $\mathrm{CT}$ section. Longitudinal and transverse diameter of the metatarsal bone were $4.86 \mathrm{~cm}$ and $4.40 \mathrm{~cm}$, respectively.

C1. Transverse anatomical section at the level of $8 \mathrm{~cm}$ below the proximal extremity of the metatarsal bones. C2. The most relevant transverse bone window CT section. Longitudinal and transverse diameter of the metatarsal bone were $3.72 \mathrm{~cm}$ and $4.28 \mathrm{~cm}$, respectively.

Notice the disappearance of the proximal osseous septum.

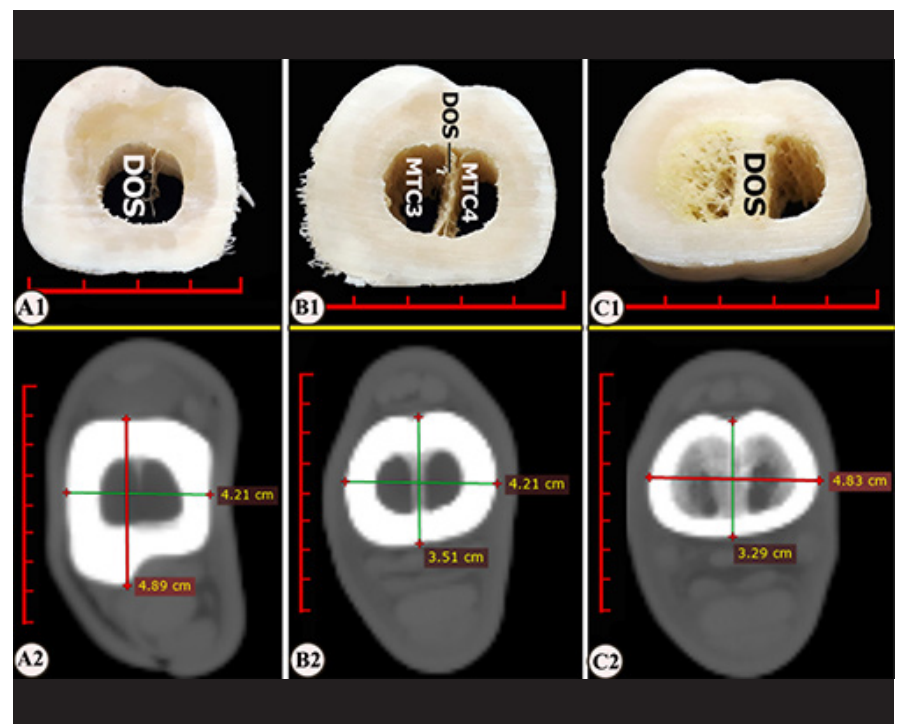

Figure 10. Transverse sections of the metatarsal bone of Zebu bull.

A1. Transverse anatomical section at the middle third about $10 \mathrm{~cm}$ above the distal extremity of the metatarsal bones. The longitudinal and transverse diameter of the metatarsal bone were $4.89 \mathrm{~cm}$ and $4.21 \mathrm{~cm}$ respectively. A2. The most relevant transverse bone window CT section. Notice the disappear of the distal osseous septum (DOS).

B1. Transverse anatomical section in the distal third at the level of $7.5 \mathrm{~cm}$ above the distal extremity of the metatarsal bones. B2. The most relevant transverse bone window CT section. The longitudinal and transverse diameter of the metatarsal bone were $3.51 \mathrm{~cm}$ and $4.21 \mathrm{~cm}$ respectively. Notice the clear septation of the distal osseous septum within the cavity.

C1. Transverse anatomical section in the distal third at the level of $5 \mathrm{~cm}$ above the distal extremity of the metatarsal bones. $\mathrm{C} 2$. The most relevant transverse bone window CT section. The longitudinal and transverse diameter of the metatarsal bone were $3.29 \mathrm{~cm}$ and $4.83 \mathrm{~cm}$ respectively. Notice the clear septation of the distal osseous septum (DOS) within the cavity. 


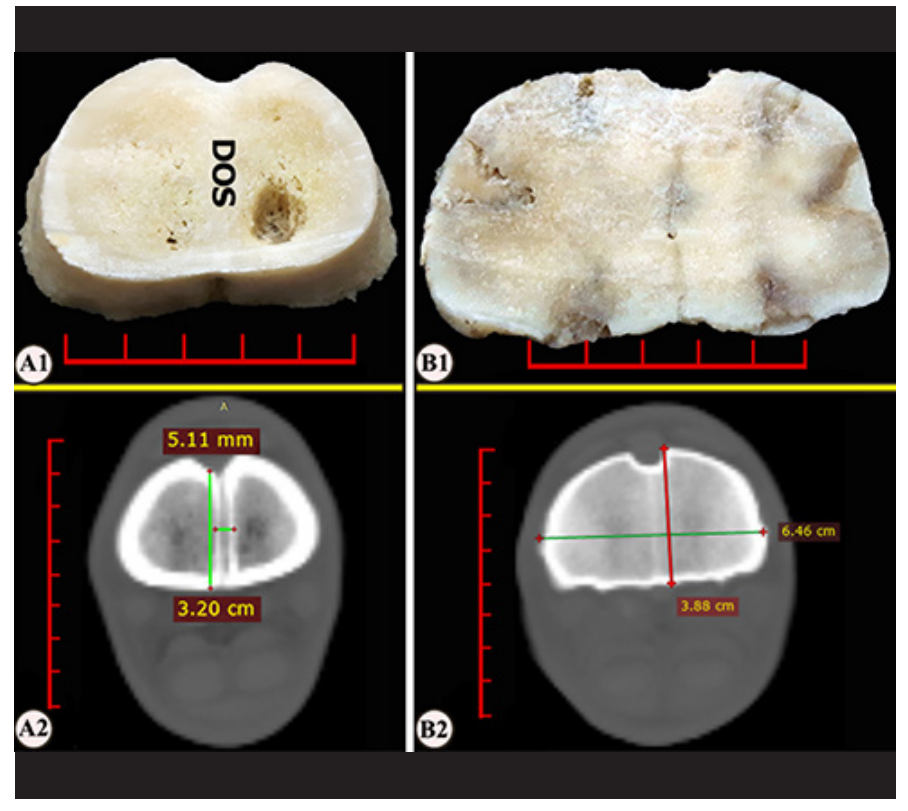

Figure 11. Transverse sections of the metatarsal bone of Zebu bull.

A1. Transverse anatomical section at the distal third about $2.5 \mathrm{~cm}$ above the distal extremity of the metatarsal bones. A2. The most relevant transverse bone window CT section. The longitudinal and transverse diameter of metatarsal bone were $5.11 \mathrm{~cm}$ and $3.20 \mathrm{~cm}$, respectively. Notice the clear septation of distal osseous septum (DOS) that projected $5.11 \mathrm{~mm}$ within the cavity.

B1. Transverse anatomical section in the distal third at the distal extremity of the metatarsal bones. B2. The most relevant transverse bone window $\mathrm{CT}$ section. The longitudinal and transverse diameter of the metatarsal bone were $3.88 \mathrm{~cm}$ and $6.46 \mathrm{~cm}$ respectively.

The shape and diameter of the medullary cavities, the thickness of the cortical zone as well as the dorsoplantar and mediolateral diameters were measured at the different levels along the length of the examined metatarsal bones of both the Egyptian Baladi and Zebu bull and presented in (Figs.3-11). In Zebu bull, the medullary cavity is incompletely divided by a vertical bony septum, which is interrupted at the middle third of the shaft. At the proximal extremity, the proximal osseous septum (POS) extended downwards into the shaft for about $7.84 \mathrm{~cm}$ dividing the medullary cavity completely into right and left parts (Figs.78). Meanwhile, a short crest was detected instead of the typical proximal osseus in some Egyptian Baladi metatarsi. At the proximal extremity, the distal osseous septum (DOS) extended upwards into the shaft for about 9.8 and $10.10 \mathrm{~cm}$ dividing the medullary cavity completely into right and left parts in the Egyptian Baladi and Zebu bull, respectively (Figs. 3, 5-6, 7 \& 9-11).

In the two species, the nutrient foramen and canal were clearly visible as attenuated dorsoplantar line just above the inter-condyloid groove of the metatarsal bone at about the level of the junction of the distal two fifths of the bone. The nutrient canal measured about $3.00 \mathrm{~cm}$ in length and $4.9 \mathrm{~mm}$ width in Egyptian Baladi, and $3.20 \mathrm{~cm}$ in length and $5.11 \mathrm{~mm}$ width in Zebu. About $2.75 \mathrm{~cm}$ proximal to inter-condyloid groove, the distal osseous septum was interrupted by the metatarsal canal.
Morphometric analysis of metatarsal bones of Egyptian Baladi and zebu bull:

The obtained morphometric data revealed significant variations among the dimensions of the metatarsal bones of the two examined bull species (Figs 12-13 and Tables 1-2). Except the diameter of the distal extremity, all the recorded parameters were greater in Zebu metatarsi compared to those of the Egyptian Baladi bull. Special attention was given to the increase of mediolateral and dorsoplantar dimensions at all levels of the shaft of the metatarsal bones of Zebu bull compared to those dimensions recorded in the metatarsi of the Egyptian Baladi bull. The total length of the bone, its diameter at the proximal extremities, and the thickness of the compact layer at the middle of the shaft were also greater in the metatarsal bones of Zebu bull than those the Egyptian Baladi bull. In the later, the proximal osseus septum was represented by a short crest meanwhile it was relatively long in Zebu bull. In addition, the distal osseus septum is longer and more extensive in Zebu metatarsi than in those of the Egyptian Baladi bull.

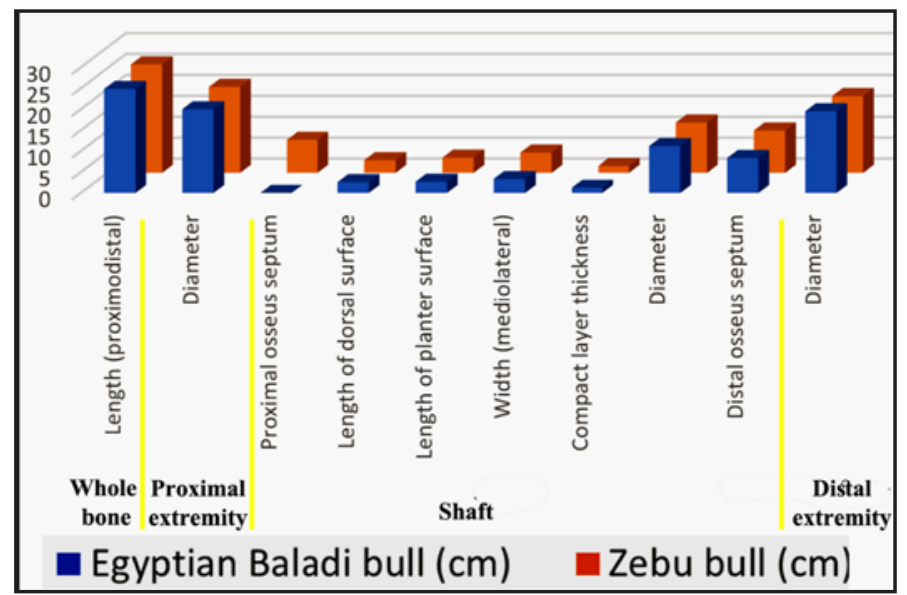

Figure 12. Diagram describing the morphometric dimensions of the metatarsal bones in Zebu (Bos Taurus indicus) and Egyptian Baladi bull (Bos Taurus Taurus).

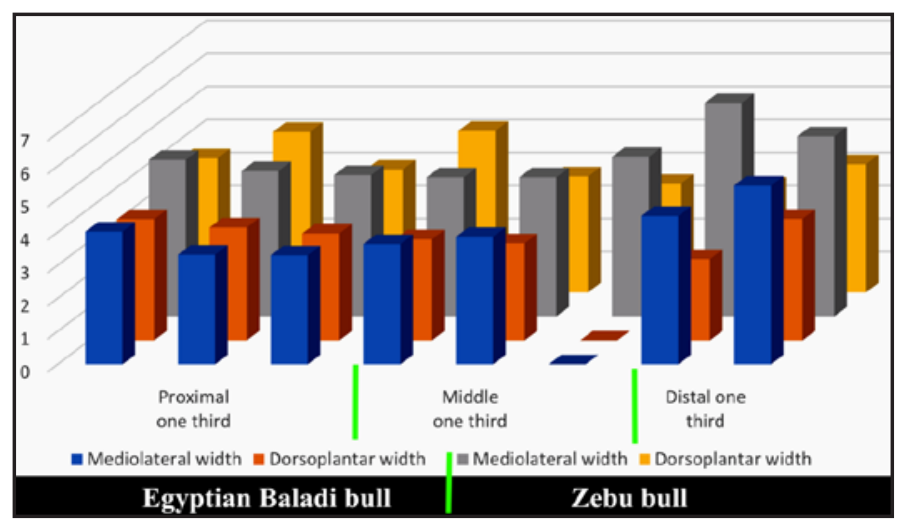

Figure 13. Diagram describing the morphometric dimensions at the proximal, middle, and distal thirds of the metatarsal bones in Zebu (Bos Taurus indicus) and Egyptian Baladi bull (Bos Taurus Taurus).

\section{Discussion}

The metatarsal bones present great morphological variations among the domestic animals and classified 
according to their size, function, and structure into two types; functional and small rudimentary bones i.e., functional five bones in dog, four in pig, two in ruminants and only one in equines ${ }^{5,7,8,12}$. Specifically in ruminants including the camel, the distal extremity of the metatarsal bones is divided into two trochleae separated by inter-condyloid groove ${ }^{6}$.

Up to our knowledge, there is a shortage of the anatomical description of the metatarsal bone in zebu bull (Bos Taurus indicus). In the present study, the metatarsal bones of the Egyptian Baladi and Zebu bull were greatly similar in terms of their gross anatomical features. However, the proximal osseous septum, which was represented by a short crest in Egyptian Baladi bull, it was extensively complete and extended from the proximal extremity distal wards into the shaft for about $7.85 \mathrm{~cm}$ in the Zebu bull. The distal osseus septum was observed in both the Egyptian Baladi bull and Zebu bull extending into the shaft for about $8.75 \mathrm{~cm}$ and $10.10 \mathrm{~cm}$ above the distal extremity, respectively. While in buffalo, the proximal and distal osseus septum were observed and these osseus septum were completely absent from the shaft ${ }^{6}$, while in the camel, the distal osseus septum was absent but the proximal osseus septum was well-developed ${ }^{6}$. In the camel, the medullary cavity of fused metacarpal and metatarsal bones are completely divided into two separate parts by complete septum which is duplicated at its distal and proximal parts ${ }^{5,8,10}$, in contrast to that observed in the current work in both Egyptian Baladi and Zebu bull and also in the buffalo ${ }^{6}$. Functionally, the current observations of the presence or absence of the proximal and distal osseous septum with the different diameter of the metatarsal bone in the examined bull species, firstly indicated that the metatarsus is subjected to the fracture at its the middle part in the Egyptian Baladi bull than the Zebu bull that confirmed the right operation of using the Zebu bull for the fatting process.

The current morphometric data revealed significant variations among the dimensions of the metatarsal bones of the two examined bull species (Table 1-2). Except the diameter of the distal extremity, all the recorded parameters were greater in Zebu metatarsi compared to those of the Egyptian Baladi bull. Special attention was given to the increase of mediolateral and dorsoplantar dimensions at all levels of the shaft of the metatarsal bones of Zebu bull compared to those dimensions recorded in the metatarsi of the Egyptian Baladi bull. The total length of the bone, its diameter at the proximal extremities, and the thickness of the compact layer at the middle of the shaft were also greater in the metatarsal bones of Zebu bull than those the Egyptian Baladi bull. In the later, the proximal osseus septum was represented by a short crest meanwhile it was relatively long in Zebu bull. In addition, the distal osseus septum is longer and more extensive in Zebu metatarsi than in those of the Egyptian Baladi bull. Functionally, the current observations confirmed that the metatarsal of the Zebu bull bears the pressures caused by the large increase in weight during the fatting process.

Substantial morphometric variations were recorded between the metatarsal bones of the two examined bull species as described in Tables 1-2. In Zebu bull, the medullary cavity is incompletely divided by a vertical bony septum, which is interrupted at the middle third of the shaft. At the proximal extremity, the proximal osseous septum (POS) extended downwards into the shaft for about $7.84 \mathrm{~cm}$ dividing the medullary cavity completely into right and left parts. Meanwhile, a short crest was detected instead of the typical proximal osseus in some Egyptian Baladi metatarsi. At the proximal extremity, the distal osseous septum (DOS) extended upwards into the shaft for about 9.8 and $10.10 \mathrm{~cm}$ dividing the medullary cavity completely into right and left parts in the Egyptian Baladi and Zebu bull, respectively. Meanwhile in the bull $^{10}$, the medullary cavity is incompletely divided by a vertical septum. At the proximal extremity, the septum extended downward for $4 \mathrm{~cm}$ while at the distal extremity it extended upward from the intertrochlear fissure $7 \mathrm{~cm}$ and the distal part of the septum is interrupted nearly at the middle by an oval area represent the distal metacarpal or metatarsal canal. Meanwhile in the camel ${ }^{6,10}$, the medullary cavity is completely divided into two separated parts by a complete septum which is duplicated at its distal and proximal parts. The medullary cavity of the buffalo is partially divided by the presence of the incomplete proximal osseous septum for about $4-5 \mathrm{~cm}$ distal to the tarsal articular surface while the distal osseous septum extended proximally for $4-5 \mathrm{~cm}^{6}$.

\section{References}

1. Abumandour, MM, NF Bassuoni, S El-Gendy, A Karkoura, and R ElBak-ary. 2020. Cross-anatomical, radiographic and computed tomographic study of the stifle joint of donkeys (Equus africanus asinus). Anat Histol Embryol 49:1-15.

2. Abumandour, MMA, NF Bassuoni, S El-Gendy, A Karkoura, and R El-Bakary. 2019. Comparative Morphological Studies of the Stifle Menisci in Donkeys, Goats and Dogs. Journal of Morphological Sciences 36:072-084.

3. Chen, S, B-Z Lin, M Baig, B Mitra, RJ Lopes, AM Santos, DA Magee,
M Azevedo, P Tarroso, and S Sasazaki. 2010. Zebu cattle are an exclusive legacy of the South Asia Neolithic. Molecular biology and evolution 27:1-6.

4. Duncan, JS, ER Singer, J Devaney, JWH Oultram, AJ Walby, BR Lester, and HJ Williams. 2013. The radiographic anatomy of the normal ovine digit, the metacarpophalangeal and metatarsophalangeal joints. Vet Res Commun 37:51-57

5. Dyce, KM, WO Sack, and CJG Wensing. 2010. Text book of Veterinary anatomy.: W.B. Saunders Company, Philadelphia, London and 
Toronto. 2010.

6. El-Shafey, A, and A Kassab. 2013. Computed Tomography and Cross-Sectional Anatomy of the Metatarsus and Digits of the Onehumped Camel ( $C$ amelus dromedarius) and Buffalo ( $B$ os bubalis). Anatomia, histologia, embryologia 42:130-137.

7. Evans, HE, and A De Lahunta. 2013. Miller's ANATOMY of the DOG fourth edition.W. B. Saunders Company, Philadelphia, 1181 pp. 2013. 8. Getty, R. 1975. The Anatomy of the Domestic Animals. Vol.1, 5th Ed., W.B. Saunders Company, Philadelpshia, USA. 1975.

9. Graml, R, G Ohmayer, F Pirchner, L Erhard, J Buchberger, and A Mostageer. 1986. Biochemical polymorphism in Egyptian Baladi cattle and their relationship with other breeds. Animal genetics 17:61-76.

10. Hifny, A, NA Misk, and MA Semieka. 1995. Radiographic studies on the manus and pes of camel and cattle. Journal of Camel Practice and Research:87-91.

11. Madalena, F, H Toledo-Alvarado, and N Cala-Moreno. 2019.
Animals That Produce Dairy Foods: Bos indicus Breeds and Bos indicus× Bos taurus Crosses.

12. Makungu, M, HB Groenewald, WM Du Plessis, M Barrows, and KN Koeppel. 2014. Osteology and Radiographic Anatomy of the Pelvis and Hind Limb of Healthy Ring- Tailed Lemurs (Lemur catta). Anatomia, histologia, embryologia 43:190-202.

13. Mostageer, A, Y Afifi, M Morsy, and A Nigm. 1987. Grading up Baladi cattle with Friesians in Egypt. Journal of Animal Breeding and Genetics (Germany, FR).

14. Nomina Anatomica Veterinaria, N. 2017. International Committee on Veterinary Gross Anatomical Nomenclature and authorized by the general assembly of the world Association of veterinary Anatomist. Knoxville, 3rd Ed. Ghent. Published by the Editorial Committee Hanover (Germany), Ghent (Belgium), Columbia, MO (U.S.A.), Rio de Janeiro (Brazil). 2017.

15. Wilson, DE, and DM Reeder. 2005. Mammal species of the world: a taxonomic and geographic reference: JHU Press. 2005.
Received: Juny 25, 2021

Accepted: July 20, 2021
Corresponding author

Mohamed Abumandour

E-mail:m.abumandour@yahoo.com or

M.abumandour@alexu.edu.eg 